\title{
Orange-based and Lemon-based Adsorbents with Controlled Grain for an Efficient Elimination of Cationic and Anionic Dyes from Textile Dyeing Wastewater
}

\section{G. Pascual}

Universitat Politècnica de Catalunya

\section{Riba-Moliner}

Universitat Politècnica de Catalunya

\section{J. M. Canal}

Universitat Politècnica de Catalunya

J. Garcia-Raurich ( $\sigma_{\text {josep.garcia.i@upc.edu ) }}$

Universitat Politècnica de Catalunya

\section{Research Article}

Keywords: cationic dye, anionic dye, adsorbent, adsorption, citrus peel, wastewater, textile dyeing

Posted Date: February 10th, 2021

DOI: https://doi.org/10.21203/rs.3.rs-177945/v1

License: (9) (7) This work is licensed under a Creative Commons Attribution 4.0 International License. Read Full License 


\section{Abstract}

Physically and chemically modified orange and lemon mesocarps are used as natural adsorbents for both cationic and anionic dyes from wastewaters of textile dyeing industry. Adsorptivity of the orange-based and lemon-based adsorbents to the dyes are studied simulating a batch and a continuous industrial process. Thus, the most suitable operating conditions to achieve the maximum adsorption yield are provided. Results demonstrate that treated orange and lemon mesocarps can be used as excellent reusable adsorbents to the removal of cationic and anionic dyes from aqueous solutions. Moreover, the recovery of the adsorbed dye is also reliable and proved.

\section{Introduction}

One of the main problems of textile dyeing industry is the treatment of the generated wastewater. Due to the environmental impact of those effluents, different treatment strategies have been studied for long time.

Traditionally, these wastewaters have been treated to eliminate colouration or dyes with chemical, combination of physical and chemical and even biological processes that are expensive because incur in operating and maintenance costs that affect the profitability of the production [1-3]. Consequently, most of the small factories are not able to absorb those costs. Because of this, adsorption emerges as an alternative economic process that has an acceptable environmental impact [4][5]. The term biosorption refers to compound capture by biomass (dead or alive), through physicochemical mechanisms like adsorption or ion exchange, involving a solid phase (adsorbent) and a liquid phase that contains the species that must be adsorbed (adsorbate) [6]. A wide range of low-cost materials with the potential to be used for biosorption processes have been studied, including wood [7][8], clay [9], ashes [10], activated muds [11], orange [12] and banana peels [13] for instance. In this sense, Annadurai and coworkers reported positive results using banana and orange peels to remove dyes like methylene blue, orange or purple from wastewaters [14]. Similarly, Banat et al. demonstrated that olive wastes and charcoal could be used as bioadsorbents in columns to remove methylene blue from wastewaters, reaching up to $80 \%$ of dye removal [15]. Concomitantly, this dye together with other cationic dyes, were also removed using passion fruit peels [16].

The current trend is to use agroindustrial wastes as an alternative for preparing bioadsorbent materials since they are cheap and effective in the elimination of metal ions [17] as long as they have been processed through physicochemical treatments [18]. On the one hand, cation exchange is the accepted mechanism for the removal of metal ions and, on the other electrostatic attractions and/or hydrogen bonds are the accepted mechanisms for dye adsorption [19][20].

On the other hand, dyes can be classified as natural or synthetic depending on their origin. Natural dyes are obtained from minerals, animals or plants and are usually considered innocuous. The main disadvantage of natural dyes is that can be found in a complex state in nature and they need to be extracted and purified. Because of that, they are limited only for specific uses which are less than those affecting synthetic dyes. Contrarily, around 10,000 different synthetic dyes are used in industries such as textile, paper, pharmaceutical, cosmetic and food, and about 70\% are azo type dyes. Regardless, the ionic character, stereochemistry and fastness properties of dyes are fundamental aspects for its industrial application. Due to the complexity of the structures of xenobiotic compounds, the removal percentage in conventional water treatment plants is very low and because of that, those compounds can be discharged without being treated [21]. The environmental impact 
includes variations in water like solids in suspension, ionic charge, toxicity, oxygen concentration and colourisation. Generally, most dyes are very persistent in wastewaters due to their solubility in water and degradation resistance that is determined by the complexity of their structure [22].

Nevertheless, there have been important advances in the use of biotech applications in the textiles industry, not just to remove colour [23] but to completely eliminate the dye [24]. Some of those advances are based in the improvement of treatments by filtration, chemical oxidation [25], and pre-treatments including anaerobic digestion, fixed film bioreactors [26], advanced oxidation reaction by Fenton reagents, electrolysis or foam flotation. Wastewater treatments based in adsorption are considered relatively new strategies. In this case, the operation process is based when a fluid and a solid adsorbent are in contact, being a superficial phenomenon through which the adsorbate remains held on the surface and in the inner pores of the solid [27-29].

In these recent years, the concepts of reuse and recycling have taken an increasingly important role in our society and it has been resulted in an increase in research and development of sustainable technologies. The experience acquired by CRESCA team in studying orange and lemon peels has allowed transforming those considered by-products into new raw materials that, with appropriate treatments, can become high added value products. In this sense, several previous studies developed by our research group demonstrated very satisfactory results in the use of orange and lemon peels as adsorbents of organic dyes for alternative textile industry wastewater treatment [30] or even as wine clarifiers, providing an alternative to conventional used products [31].

Here, the evaluation of the adsorption capacity of modified mesocarps of orange and lemon peels to retain cationic and anionic dyes from textile dyeing industry wastewaters is presented. To obtain the adsorbents, orange and lemon peels are previously subjected to a physicochemical treatment. The adsorption capacity of the adsorbents is tested in batch and in continuous processes with different cationic and anionic dyes. Parameters such as the nature of the adsorbent, the concentration of the adsorbent, $\mathrm{pH}$ of the adsorption process, time of contact, hydration degree and number of column pass are evaluated by analysing the concentration of the dye in the residual liquor fraction by UV-Vis spectroscopy.

\section{Materials And Methods}

\section{Materials}

Orange and lemons peels were collected from local fruit stores. Anionic dyes: Acid Blue $264\left(\mathrm{C}_{29} \mathrm{H}_{28} \mathrm{~N}_{3} \mathrm{NaO}_{6} \mathrm{~S}_{2}\right)$, Acid Yellow $49\left(\mathrm{C}_{16} \mathrm{H}_{12} \mathrm{Cl}_{2} \mathrm{~N}_{5} \mathrm{O}_{3} \mathrm{~S}\right)$ and Acid Red $337\left(\mathrm{C}_{17} \mathrm{H}_{11} \mathrm{~F}_{3} \mathrm{~N}_{3} \mathrm{NaO}_{4} \mathrm{~S}\right)$. Cationic dyes: Basic Blue 3 $\left(\mathrm{C}_{20} \mathrm{H}_{26} \mathrm{ClN}_{3} \mathrm{O}\right)$, Basic Yellow $21\left(\mathrm{C}_{22} \mathrm{H}_{25} \mathrm{CIN}_{2}\right)$, Basic Red $18\left(\mathrm{C}_{19} \mathrm{H}_{25} \mathrm{Cl}_{2} \mathrm{~N}_{5} \mathrm{O}_{2}\right)$ and Basic Green $4\left(\mathrm{C}_{23} \mathrm{H}_{25} \mathrm{ClN}_{2}\right)$. Filters of $0.45 \mu \mathrm{m}$ pore of Millex were used in the batch process.

\section{Physical treatment of peels}

An initial manual washing of the oranges and lemons peels was carried out to eliminate added waxes, resins and possible soil of the epicarp with tap water and conventional soap at room temperature. After dried with continuous air flow, they were cut with an ice mincer until achieve particle sizes between 0,5-1 $\mu \mathrm{m}$, according to previous studies performed by Arjona et al.[30] 


\section{Chemical treatment of peels}

Due to the different nature of the studied dyes (anionic and cationic), the chemical treatment applied to the peels was different as well. With the objective to achieve an adsorbent capable to adsorb anionic dyes, peels followed the procedure:

1. Acidic treatment: to remove pectins and other compounds such as $\beta$-carotene $(50 \mathrm{~g}$ peel $/ 500 \mathrm{~mL}$ deionised water, $\mathrm{pH}=3-4$, ultrasonic agitation, $45 \mathrm{~min}$ ).

2. Alkaline treatment: saponification of peels, concretely cellulose, hemicellulose and remaining pectin fraction (50 g peel, $2.5 \mathrm{~g} \mathrm{Ca}(\mathrm{OH})_{2}$, the necessary volume of deionised water, $\mathrm{pH}>10$, ultrasonic agitation, 45 $\min )$.

3. Acidic treatment: modification of ionic charge $(50 \mathrm{~g}$ peel $/ 500 \mathrm{~mL}$ deionised water, $\mathrm{pH}=3-4$, ultrasonic agitation, $45 \mathrm{~min})$.

4. Neutralisation

5. Dry

The third step was avoided when peels were prepared to adsorb cationic dyes.

\section{Batch process}

In the discontinuous or batch process, the amount of adsorbent $(0.50,0.75$ and $1.00 \mathrm{~g})$, type of dye (anionic and cationic), concentration of dye (30,60, 90, 120 and $240 \mathrm{ppm}), \mathrm{pH}$ (as-it-is, acid and alkaline), adsorption time (5, $10,15,30$ and $45 \mathrm{~min}$ for anionic and 15, 30, 45, 60 and $75 \mathrm{~min}$ for cationic) and the initial hydration degree of orange and lemon adsorbent parameters were studied. To do this, $25 \mathrm{~mL}$ of a solution of dye was prepared and mixed with the corresponding adsorbent at $20^{\circ} \mathrm{C}$. Then, the sample was filtered and the concentration of dye in the liquor was analysed by UV-Vis (Shimadzu UV-1800).

\section{Continuous process}

Continuous process conditions were set once the conditions for the batch process were established. For this reason, only the dyes that presented the highest adsorption percentage in the batch process were tested in the continuous (cationic green and anionic blue). Moreover, two types of columns were evaluated, a small column Afora 5831 ( $\mathrm{n}^{\circ} 0$ porous plate, glass key with $2 / 3 \mathrm{~mm}$ key passage, $10 \mathrm{~mm}$ internal diameter, $200 \mathrm{~mm}$ useful length) and a larger column Afora 5855 ( $n^{\circ} 0$ porous plate, glass key with 2/3 mm key pass, $30 \mathrm{~mm}$ internal diameter and $500 \mathrm{~mm}$ useful length). The first column was used to perform experiments towards the determination of the evolution of the adsorbents adsorption to the column pass volume $(5 \mathrm{~g}$ of adsorbent, 30 ppm dye solution, $25 \mathrm{~mL} / \mathrm{min}$, recovered adsorbent was washed with ethyl alcohol) and, the second, to determine the influence of the flow rate $(125,43$ and $23 \mathrm{~mL} / \mathrm{min}$ for $20 \mathrm{~g}$ of adsorbent) together with the concentration of dye ( $20 \mathrm{~g}$ adsorbent with 30 and $60 \mathrm{ppm}$ of dye) in the dye adsorption yield.

\section{Results And Discussion}

\section{Batch process}


The influence of the amount of the chemically and physically treated orange and lemon peels (adsorbents) to the cationic dyes adsorption was firstly evaluated. To do this, cationic dyes were initially analysed by UV-Vis absorption spectroscopy in order to obtain the wavelengths corresponding to the peaks of maximum absorption. The resulting spectra indicated that the maximum absorption signal for each one of the cationic dyes were found at $652 \mathrm{~nm}, 488 \mathrm{~nm}, 415.5$ and $613.5 \mathrm{~nm}$ for blue, red, yellow and green, respectively. Afterwards, adsorption experiments with orange-based and lemon-based adsorbents with the mentioned dyes were carried out. A clear liquid fraction was obtained after $45 \mathrm{~min}$ when $0.5,0.75$ and $1.00 \mathrm{~g}$ of orange-based and lemon-based adsorbents where put in contact with cationic dye, indicating a high adsorption capacity of both adsorbents (Fig. 1).

Those liquid fractions or liquors where subsequently analysed by UV-Vis spectroscopy and the percentage of adsorbed dye was calculated for each amount of adsorbent used (Fig. 2).

Similar adsorption values were obtained for orange-based and lemon-based adsorbents, however the overall percentage was slightly higher in the case of orange-based adsorbent. Blue, yellow and green cationic dyes where increasingly adsorbed with the concentration of both adsorbents, although a discreet increase of a $0.25 \%$ between 0.75 and $1.00 \mathrm{~g}$ of orange-based adsorbent was spotted for the green. Concretely, in the case of yellow, differences in the adsorption were found in the origin of the adsorbent, being higher in the case of orangebased. Contrastingly, red cationic dye was similarly adsorbent for both adsorbents, presumably indicating an important correlation between the chemical nature of the dyes to the adsorption results.

Furthermore, the capacity of the orange-based and lemon-based adsorbents was extensively evaluated with anionic dyes (Fig. 3).

In contrast to the results obtained for cationic, blue anionic dye was highly retained by the lemon-based adsorbent rather the orange-based, presenting an averaged difference of the $31.66 \%$. Nevertheless, the concentration of adsorbent was essentially an independent parameter when values were compared within the same adsorbent for this dye. On the other hand, the percentage of red anionic dye adsorbed increased with the amount of adsorbent, similarly to yellow anionic dye. However, yellow anionic dye was the only dye that showed a higher retention with orange-based adsorbent than the other one. Those observed differences in the adsorption with the different dyes may have probably been influenced by the stereochemistry of the molecule of the dye due to the position and the steric hindrance of the reactive groups of each case. Moreover, an amount of $1.00 \mathrm{~g}$ of adsorbent was established to be the more suitable concentration on dye adsorption and so, subsequent experiments were set with this parameter.

The influence of the dye concentration in the adsorption capacity of the adsorbents was also evaluated maintaining at $1.00 \mathrm{~g}$ the amount of the adsorbent. The assay was performed with the dyes that showed the strongest and the weakest adsorption affinity to the adsorbents. Thus, green and yellow cationic dyes and blue and yellow anionic dyes were tested with different initial concentrations, ranging from 30 to 240 ppm (Table 1). 
Table 1

Percentages of adsorbed dyes according to its initial concentration for orange-based and lemon-based adsorbents.

\begin{tabular}{|c|c|c|c|c|c|c|c|}
\hline \multirow[t]{2}{*}{ Type of dye } & \multirow[t]{2}{*}{ Dye } & \multirow[t]{2}{*}{ Adsorbent } & \multicolumn{5}{|c|}{ Initial concentration (ppm) } \\
\hline & & & 30 & 60 & 90 & 120 & 240 \\
\hline \multirow[t]{4}{*}{ Cationic } & \multirow[t]{2}{*}{ Green } & Orange & 96.30 & 96.17 & 96.64 & 97.59 & 96.72 \\
\hline & & Lemon & 96.30 & 96.17 & 96.64 & 97.59 & 97.85 \\
\hline & \multirow[t]{2}{*}{ Yellow } & Orange & 72.65 & 97.57 & 98.31 & 98.75 & 81.91 \\
\hline & & Lemon & 60.75 & 98.81 & 99.04 & 99.33 & 91.56 \\
\hline \multirow[t]{4}{*}{ Anionic } & \multirow[t]{2}{*}{ Blue } & Orange & 71.5 & 91.9 & 94.3 & 88.3 & 85.3 \\
\hline & & Lemon & 95.0 & 81.7 & 74.7 & 67.3 & 69.7 \\
\hline & \multirow[t]{2}{*}{ Yellow } & Orange & 48.0 & 84.8 & 79.2 & 68.0 & 65.9 \\
\hline & & Lemon & 40.4 & 70.4 & 60.2 & 36.3 & 43.7 \\
\hline
\end{tabular}

Both, orange-based and lemon based-adsorbents did not exhibit significant differences in the adsorption of green cationic dye, resulting in notably high adsorption efficiencies even at higher concentrations. On the contrary, yellow cationic dye experienced a maximum percentage adsorbed between 90 and 120 ppm for both adsorbents, and then a moderate decay at higher dye concentrations. Due to the poorer affinity between yellow cationic dye and the adsorbents respect to the green homologue, a major quantity of the yellow was necessary to achieve similar adsorption results as green, according to previous observations. In the case of anionic dyes, orange-based adsorbent experienced a maximum adsorption peak at 90 ppm of blue dye, however at higher concentrations a progressive decreasing of this adsorption was spotted. On the other hand, when lemon-based adsorbent was put in contact with blue anionic dye, an almost lineal decrease between 30 and 120 ppm could be observed $\left(y=-0.3003 x+102.2, R^{2}=0.97\right)$, indicating the highest adsorption efficiency at the lowest dye concentration. As expected due to the previous results, yellow anionic dye showed discreet adsorption results for both types of adsorbent, presenting a maximum at $60 \mathrm{ppm}$. Even though, next assays were performed with a concentration of $30 \mathrm{ppm}$ of dye.

Another parameter that may greatly influence the capacity of dye adsorption of adsorbents is the pH value. For this reason, adsorption experiments were carried out, comparing different $\mathrm{pH}$ values: as-it-is, acid $(\mathrm{pH}=4$ and 2$)$ and alkaline ( $\mathrm{pH}=10$ and 12) (Fig. 4).

Experiments with cationic dyes revealed that the capacity to adsorb red and green dyes was not significantly affected by the $\mathrm{pH}$. However, blue and yellow dyes were greatly retained with an unmodified pH value, as-it-is, for both adsorbents. Orange-based adsorbent resulted in higher values of adsorption when the type of adsorbent was compared. Furthermore, in the case of anionic dyes, the adsorption capacity experienced a progressive decrease with the increase of the $\mathrm{pH}$ values for red and yellow dyes. On the other hand, the percentage of adsorbed blue dye kept almost invariable along the different values of $\mathrm{pH}$. Contrary to the cationic, anionic dyes were better adsorbed by the lemon-based adsorbent. Because in the most cases higher absorption results were obtained by the $\mathrm{pH}$ as-it-is, the two-type adsorbents with unmodified $\mathrm{pH}$ were concluded to be the most suitable for dye adsorption. 
Moreover, the adsorption time or the contact time between the adsorbent and the dye solution was also determined. Adsorption times were different according to the nature of the dyes because previous results demonstrated a faster adsorption of anionic dyes than cationic. Both, orange-based and lemon-based adsorbents could retain an initial increasing percentage of cationic dyes between the first 30 min and then, a plateau appeared (Fig. 5). Similar behaviour was observed in the case of anionic dyes, however the plateau appeared after 15 min of contact time.

Within cationic dyes, green was the fastest and the highest percentage dye that was adsorbed by both adsorbents and yellow the lesser in all senses, in concordance with previous observed results. On the other hand, blue and yellow anionic dyes experienced a similar behaviour as the adsorption affinity assays exposed above, being the more and faster adsorbed the blue, and the lesser and slowest the yellow. Contact times of 30 min for cationic dyes and 15 min for anionic dyes were established to be suitable to obtain adequate adsorptivities with those adsorbents.

All experiments were carried out using dried orange-based and lemon-based adsorbents. Nevertheless, the influence of the hydration degree of the adsorbents to the capacity of adsorption was determined. To do this, same experiments performed for the determination of the adequate contact time between adsorbent and dyes were repeated with hydrated adsorbents. With the objective to achieve a 'hydrated' state, adsorbents were left in contact with distilled water $24 \mathrm{~h}$ before conducting the assay. Results demonstrated that hydrated adsorbents could retain more effectively cationic and anionic dyes, especially in the case of yellow dyes, whose affinities to the dry adsorbents were the weakest (Fig. 6). Optimal contact times and its behaviour appeared to be the same for hydrated than for dry adsorbents. Consequently, hydrated adsorbent was concluded to be the most suitable state to the adsorption of cationic and anionic dyes.

\section{Continuous process}

The determination of the adsorption capacities of orange-based and lemon-based adsorbents in a continuous process were developed after the optimum conditions were established in a batch process. Continuous process experiments were conducted using the dyestuffs that presented the highest adsorption percentages in the batch process and so, green for cationic dyes and blue for anionic dues were tested. First, an experiment to determine the evolution of adsorption of the adsorbents according to the volume that passes through was conducted in a small column. The eluted fluid from the column was collected and used in a second elution through the recovered adsorbent, simulating the effect of a second column in series. This process was repeated a third time, simulating a third column in series. The capacity of adsorption of the adsorbents decreased as the elutions of dyestuffs developed, as expected, indicating a decrease of the adsorbent yield (Fig. 7). In the case of green cationic dye, after the first elution or column, the percentage of adsorbed dye was reduced down to a $18 \%$ when orange-based adsorbent was used and a $2 \%$ with the lemon-based. However, this percentage of dye adsorbed increased up to $76 \%$ and to $19 \%$ for orange-based and lemon-based, respectively, when the adsorbent was recovered and a second serial column was simulated. At the end of the third elution, the amount of dye adsorbed raised up to $90 \%$ in the case of the orange-based adsorbent and up to $59 \%$ in the case of the lemonbased adsorbent. A preferentially adsorption of the cationic dyes by orange-based adsorbent could be concluded. 
On the other hand, a $20 \%$ of blue anionic dye could be adsorbed by the orange-based adsorbent, similarly to the lemon-based, which was $18 \%$ (Fig. 7). Afterwards, the second column was able to retain up to $48 \%$ and $47 \%$ of dye when orange-based and lemon-based where used as adsorbents, respectively. Finally, after the third elution, the capacity of the orange-based and lemon-based adsorbents increased up to $67 \%$ and $71 \%$, respectively. In contrast to cationic dyes, anionic dyes did not show significant contrast in adsorptivity values when the different types of adsorbents where compared.

Additionally, the evolution of the adsorption capacity of the adsorbents was investigated at different flow rates. This part of the study was performed with green cationic dye and orange-based adsorbent due to the promising obtained results. Similarly to the previous part, three serial columns disposition was simulated, so the fluid recovered at the end of the first column pass was sequentially passed again two more times. Although the maximum flow rate studied presented an adsorption of $90 \%$, the elution was not stable (Table 2 ). The stabilisation of the elution was achieved at $23 \mathrm{~mL} / \mathrm{min}$, where a $100 \%$ of the dye was adsorbed at the $2 \mathrm{nd}$ column. Starting from the minimum flow rate, this was progressively increased until a decreasing of the adsorption was not observed together with a stable elution. In this way, $43 \mathrm{~mL} / \mathrm{min}$ was found to be the more balanced flow rate.

Table 2

Percentages of adsorbed dye according to the flow rate and column pass.

\begin{tabular}{|c|c|c|c|c|c|c|c|c|c|}
\hline & \multicolumn{9}{|c|}{ Flow rate (mL/min) } \\
\hline & 125 & & & 43 & & & 23 & & \\
\hline & $\begin{array}{l}\text { 1st } \\
\text { column }\end{array}$ & $\begin{array}{l}\text { 2nd } \\
\text { column }\end{array}$ & $\begin{array}{l}\text { 3rd } \\
\text { column }\end{array}$ & $\begin{array}{l}1 \text { st } \\
\text { column }\end{array}$ & $\begin{array}{l}\text { 2nd } \\
\text { column }\end{array}$ & $\begin{array}{l}\text { 3rd } \\
\text { column }\end{array}$ & $\begin{array}{l}\text { 1st } \\
\text { column }\end{array}$ & $\begin{array}{l}\text { 2nd } \\
\text { column }\end{array}$ & $\begin{array}{l}\text { 3rd } \\
\text { column }\end{array}$ \\
\hline $\begin{array}{l}\text { Adsorbed } \\
\text { dye (\%) }\end{array}$ & 86.1 & 3.6 & 1.0 & 97.4 & 2.1 & 0.0 & 98.0 & 2.0 & 0.0 \\
\hline
\end{tabular}

Once the flow rate was established, the adsorption capacity of the adsorbents was evaluated at different green cationic and blue cationic dyes concentration in order to observe differences in the adsorption yield. Results showed that, excepting for the elution of the green dye with lemon-based adsorbent, more promising results were obtained when the concentration of the dye was 60 ppm (Table 3). Thus, the concentration of dye with the utmost efficiency of the adsorbent could be established. Moreover, higher adsorption percentages were obtained with orange-based adsorbent when the types of adsorbents were compared within the same cationic dye. Contrastingly, the most suitable type of adsorbent to retain anionic dye was the lemon-based, in concordance with the previous observed results. 
Table 3

Percentages of adsorbed dyes according to the initial dye concentration for each type of adsorbent and column pass.

\begin{tabular}{|c|c|c|c|c|c|c|c|c|}
\hline \multicolumn{9}{|c|}{ Dye concentration (ppm) } \\
\hline & & & \multicolumn{3}{|l|}{30} & \multicolumn{3}{|l|}{60} \\
\hline & Dye & $\begin{array}{l}\text { Adsorbent } \\
\text { type }\end{array}$ & $\begin{array}{l}\text { 1st } \\
\text { column }\end{array}$ & $\begin{array}{l}\text { 2nd } \\
\text { column }\end{array}$ & $\begin{array}{l}\text { 3rd } \\
\text { column }\end{array}$ & $\begin{array}{l}\text { 1st } \\
\text { column }\end{array}$ & $\begin{array}{l}\text { 2nd } \\
\text { column }\end{array}$ & $\begin{array}{l}\text { 3rd } \\
\text { column }\end{array}$ \\
\hline \multirow{4}{*}{$\begin{array}{l}\text { Adsorbed } \\
\text { dye (\%) }\end{array}$} & \multirow[t]{2}{*}{ Green } & Orange & 98.0 & 1.5 & 0.0 & 97.5 & 2.5 & 0.0 \\
\hline & & Lemon & 90.7 & 7.7 & 1.5 & 84.0 & 13.6 & 2.1 \\
\hline & \multirow[t]{2}{*}{ Blue } & Orange & 57.0 & 29.9 & 2.6 & 67.4 & 25.0 & 4.2 \\
\hline & & Lemon & 42.1 & 44.2 & 6.3 & 93.8 & 2.5 & 0.0 \\
\hline
\end{tabular}

\section{Conclusions}

In this manuscript, the successful use of orange-based and lemon-based peels as adsorbents after some treatments to the adsorption of cationic and anionic dyes from textile dyeing wastewater has been demonstrated. The study has been conducted simulating two industrial processes, a batch and a continuous. From the batch process, a concentration of dye of $30 \mathrm{ppm}$, without the modification of the dyestuff, contact times between the dye and adsorbent of 30 min for cationic dyes and 15 min for anionic together with a hydrated adsorbent were the most favourable conditions. Moreover, the behaviour of orange-based and lemonbased adsorbents for cationic dyes has converged at concentrations of dye above $30 \mathrm{ppm}$.

In the case of the continuous process, the most suitable conditions of flow rate have been found at $43 \mathrm{~mL} / \mathrm{min}$, being the orange-based adsorbent the more promising for cationic dyes and lemon-based for anionic dyes. Furthermore, it has been demonstrated that the column efficiency increased with the dyed wastewater concentration, exhibiting an increase of the double of the adsorption of dye when the initial concentration increased from 30 ppm to 60 ppm for cationic dyes and more than four times with the yellow anionic dye. Finally, the recovery of the adsorbed dye by ethyl alcohol, allowing the regeneration of the column until seven times at least has been also demonstrated.

This study is a contribution to the circular economy since it takes advantage of agricultural wastes from the industry of juice production to transform them into bio-based adsorbents towards the purification of coloured wastewaters from dyeing textile materials.

\section{Declarations}

\section{Disclosure statement}

No potential conflict of interest was reported by the authors.

\section{References}


1. Hauser, P. Advances in Treating Textile Effluent, IntechOpen, 2011; ISBN 9789533077048.

2. Soares, P.A.; Souza, R.; Soler, J.; Silva, T.F.C. V; Souza, S.M.A.G.U.; Boaventura, R.A.R.; Vilar, V.J.P. Sep. Purif. Technol. 172, 450-462, 2017.

3. Donkadokula, N.Y.; Kola, A.K.; Naz, I.; Saroj, D. Rev. Environ. Sci. Bio/Technology 19, 543-560, 2020.

4. Liu, Y.; Zhao, Y.; Cheng, W.; Zhang, T. J. Colloid Interface Sci. 579, 766-777, 2020.

5. Rashed, M.N. Adsorption Technique for the Removal of Organic Pollutants from Water and Wastewater, Organic Pollutants - Monitoring, Risk and Treatment, IntechOpen, Ed.; 2013;

6. Park, D.; Yun, Y.-S.; Park, J.M. Biotechnol. Bioprocess Eng. 15, 86-102, 2010.

7. Kelm, M.A.P.; da Silva Júnior, M.J.; de Barros Holanda, S.H.; de Araujo, C.M.B.; de Assis Filho, R.B.; Freitas, E.J.; dos Santos, D.R.; da Motta Sobrinho, M.A. Environ. Sci. Pollut. Res. 26, 28558-28573, 2019.

8. Naeem, H.; Hassan, A. Effectiveness \& economy of sawdust wood adsorbents in removing anionic dyes of aqueous solutions.; 2018.

9. Kausar, A.; Iqbal, M.; Javed, A.; Aftab, K.; Nazli, Z.-H.; Bhatti, H.N.; Nouren, S. J. Mol. Liq. 256, 395-407, 2018.

10. Mor, S.; Chhavi, M.K.; Sushil, K.K.; Ravindra, K. Environ. Dev. Sustain. 20, 625-639, 2018.

11. Sarvajith, M.; Reddy, G.K.K.; Nancharaiah, Y. V J. Hazard. Mater. 342, 536-543, 2018.

12. Namasivayam, C.; Muniasamy, N.; Gayatri, K.; Rani, M.; Ranganathan, K. Bioresour. Technol. 57, 37-43, 1996.

13. Temesgen, F.; Gabbiye, N.; Sahu, O. Surfaces and Interfaces 12, 151-159, 2018.

14. Annadurai, G.; Juang, R.-S.; Lee, D.-J. J. Hazard. Mater. 92, 263-274, 2002.

15. Banat, F.; Al-Asheh, S.; Al-Ahmad, R.; Bni-Khalid, F. Bioresour. Technol. 98, 3017-3025, 2007.

16. Pavan, F.A.; Mazzocato, A.C.; Gushikem, Y. Bioresour. Technol. 99, 3162-3165, 2008.

17. Fu, F.; Wang, Q. J. Environ. Manage. 92, 407-418, 2011.

18. Vijayaraghavan, K.; Balasubramanian, R. J. Environ. Manage. 160, 283-296, 2015.

19. Al-Ghouti, M.A.; Al-Absi, R.S. Sci. Rep. 10, 15928, 2020.

20. Sivakumar, P.; Palanisamy, N. Adv. Appl. Sci. Reserach 1, 58-65, 2010.

21. Gupta, V.K.; Suhas J. Environ. Manage. 90, 2313-2342, 2009.

22. Buitrón, G.; Quezada, M.; Moreno, G. Bioresour. Technol. 92, 143-149, 2004.

23. Crini, G. Dye. Pigment. 77, 415-426, 2008.

24. Doğan, M.; Özdemir, Y.; Alkan, M. Dye. Pigment. 75, 701-713, 2007.

25. Sharma, K.P.; Sharma, S.; Sharma, S.; Singh, P.K.; Kumar, S.; Grover, R.; Sharma, P.K. Chemosphere 69, 4854, 2007.

26. Şen, S.; Demirer, G.N. Water Res. 37, 1868-1878, 2003.

27. Wang, S.; Li, H. Dye. Pigment. 72, 308-314, 2007.

28. Eren, E.; Afsin, B. Dye. Pigment. 73, 162-167, 2007.

29. Wang, S.; Zhu, Z.H. Dye. Pigment. 75, 306-314, 2007.

30. Arjona, A.; Canal, J.M.; García Raurich, J. IJOEAR 4, 14-27, 2018. 
31. García-Raurich, J.; Vázquez-Ricard, A.; Pallarès-Andreu, M.; Monagas Asensio, P.; Almajano Pablos, M.P. Int. J. Environ. Agric. Res. 3, 1-11, 2019.

\section{Figures}

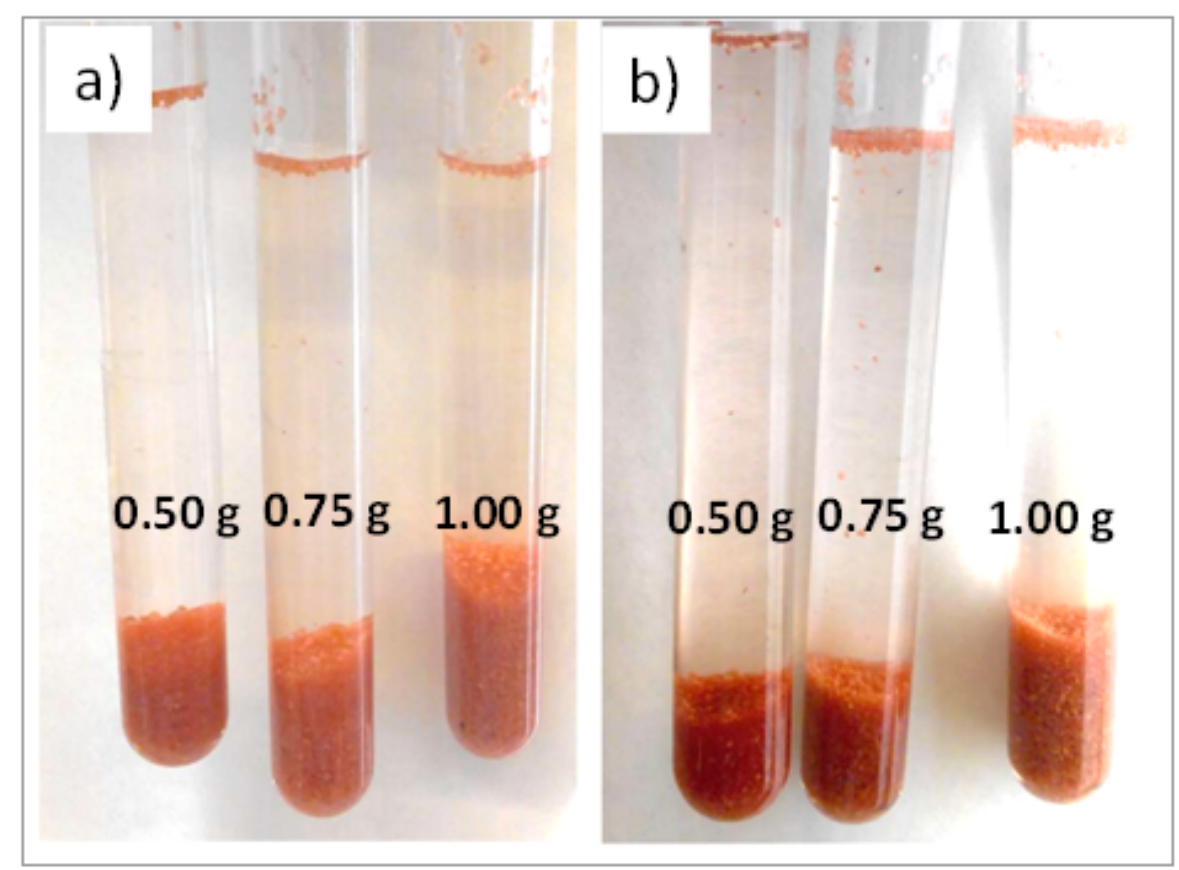

Figure 1

a) Orange-based and b) lemon-based adsorbents in different concentrations after adsorption process with cationic red dye.
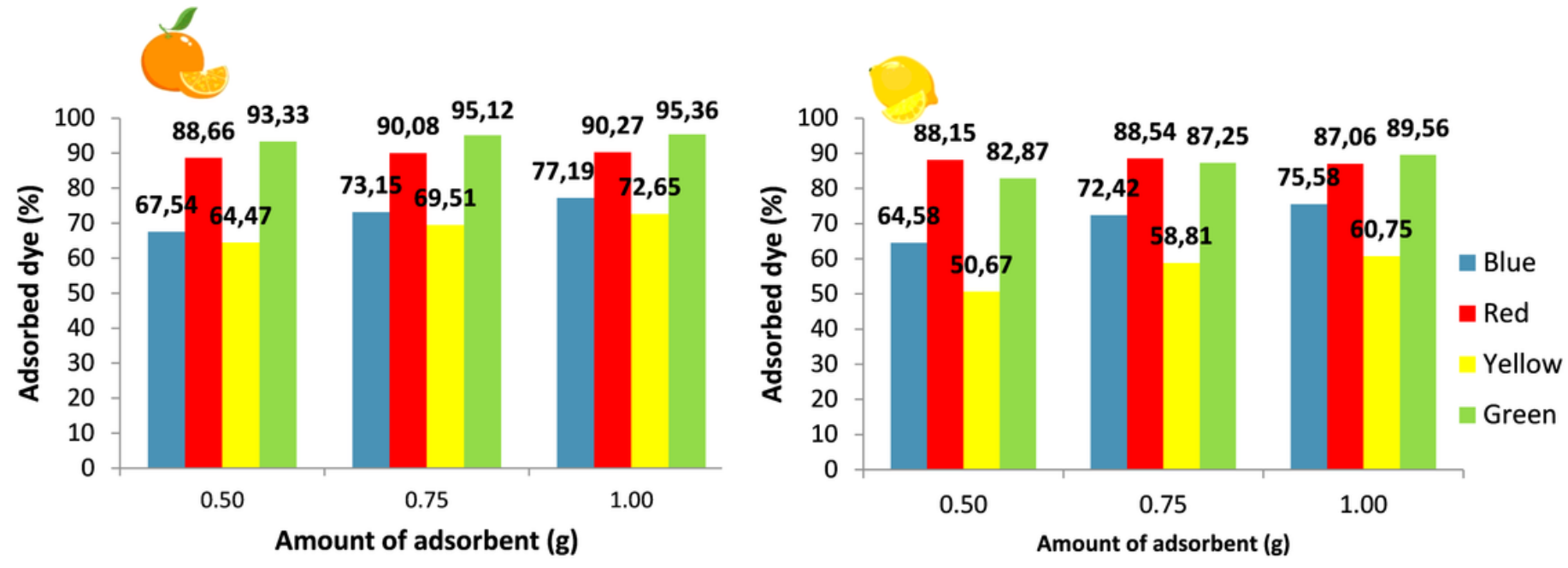

Figure 2

Percentages of adsorbed cationic dyes according to the amounts of (left) orange-based and (right) lemonbased adsorbents. 

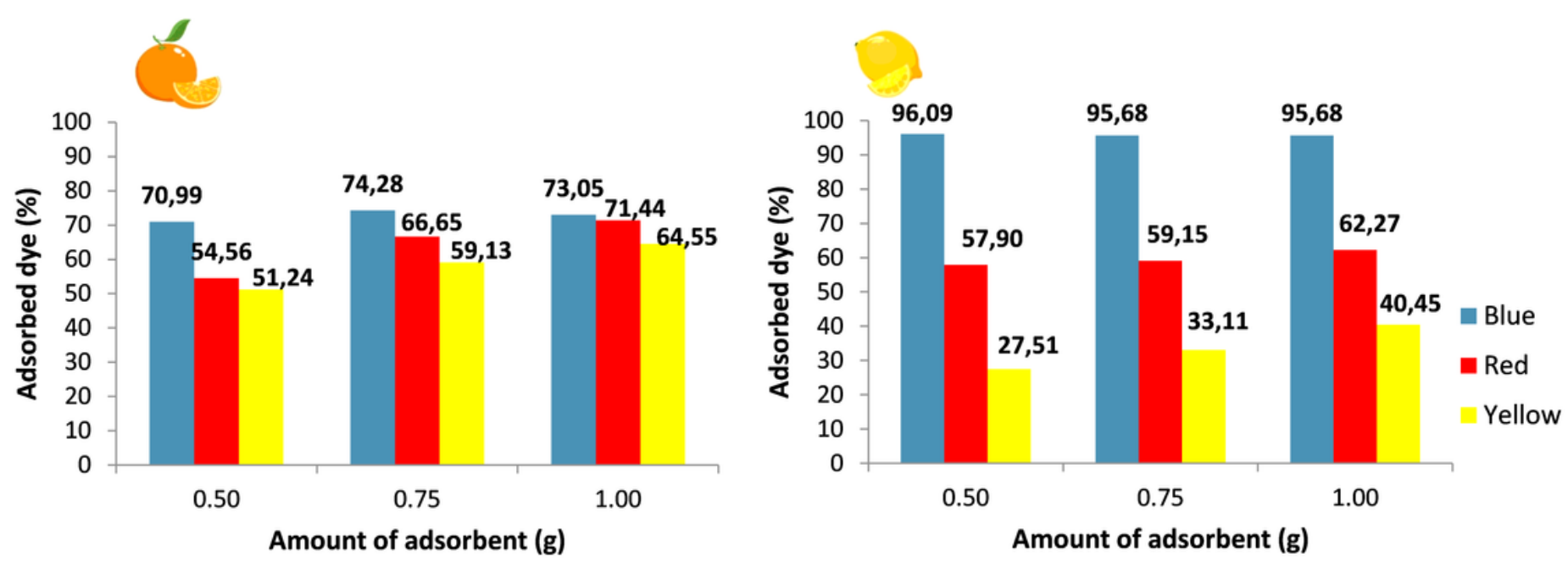

Figure 3

Percentages of adsorbed anionic dyes according to the amounts of (left) orange-based and (right) lemon-based adsorbents.
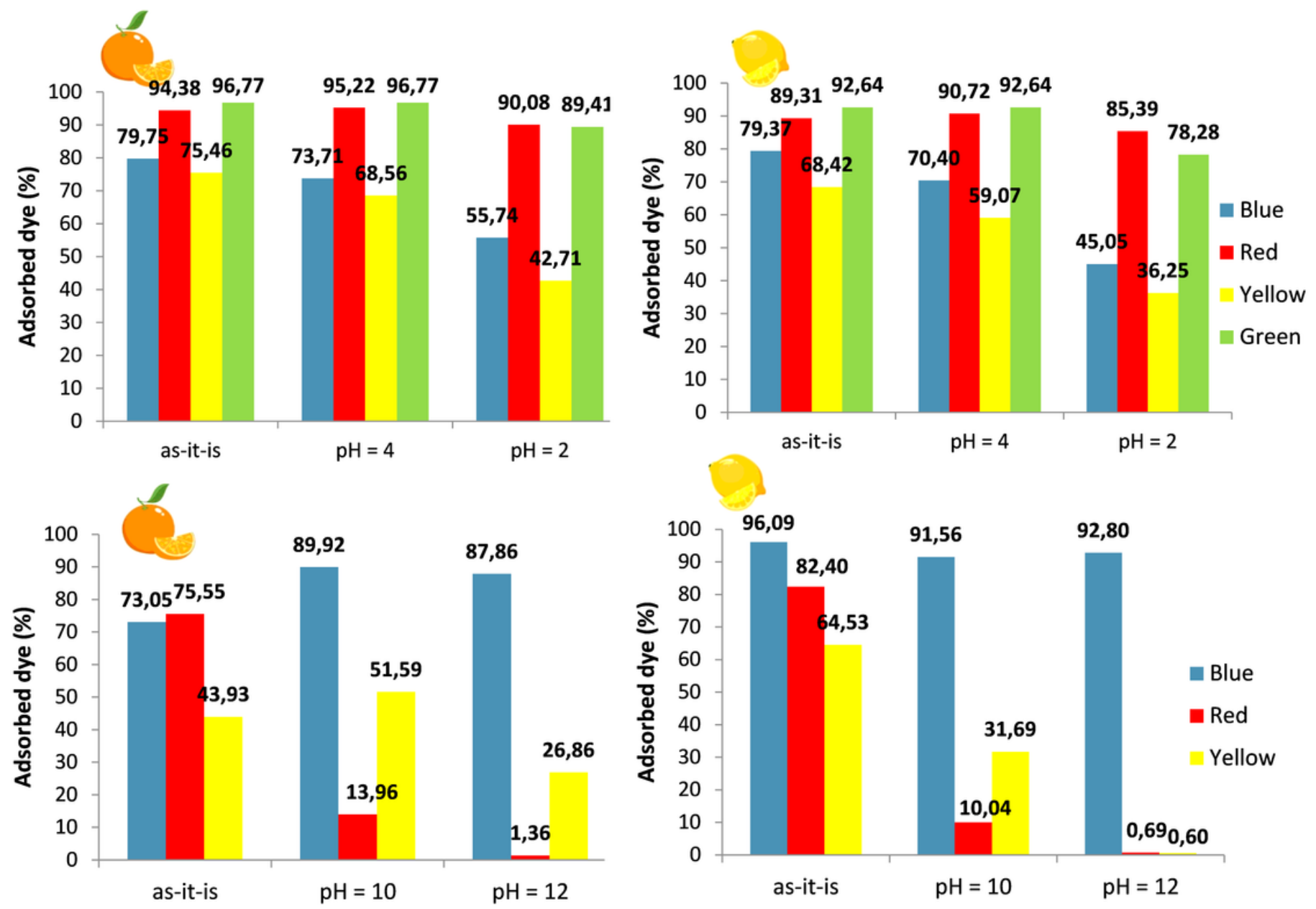

Figure 4

Percentages of adsorbed (top) cationic and (bottom) anionic dyes according to the different pH values for (left) orange-based and (right) lemon-based adsorbents. 

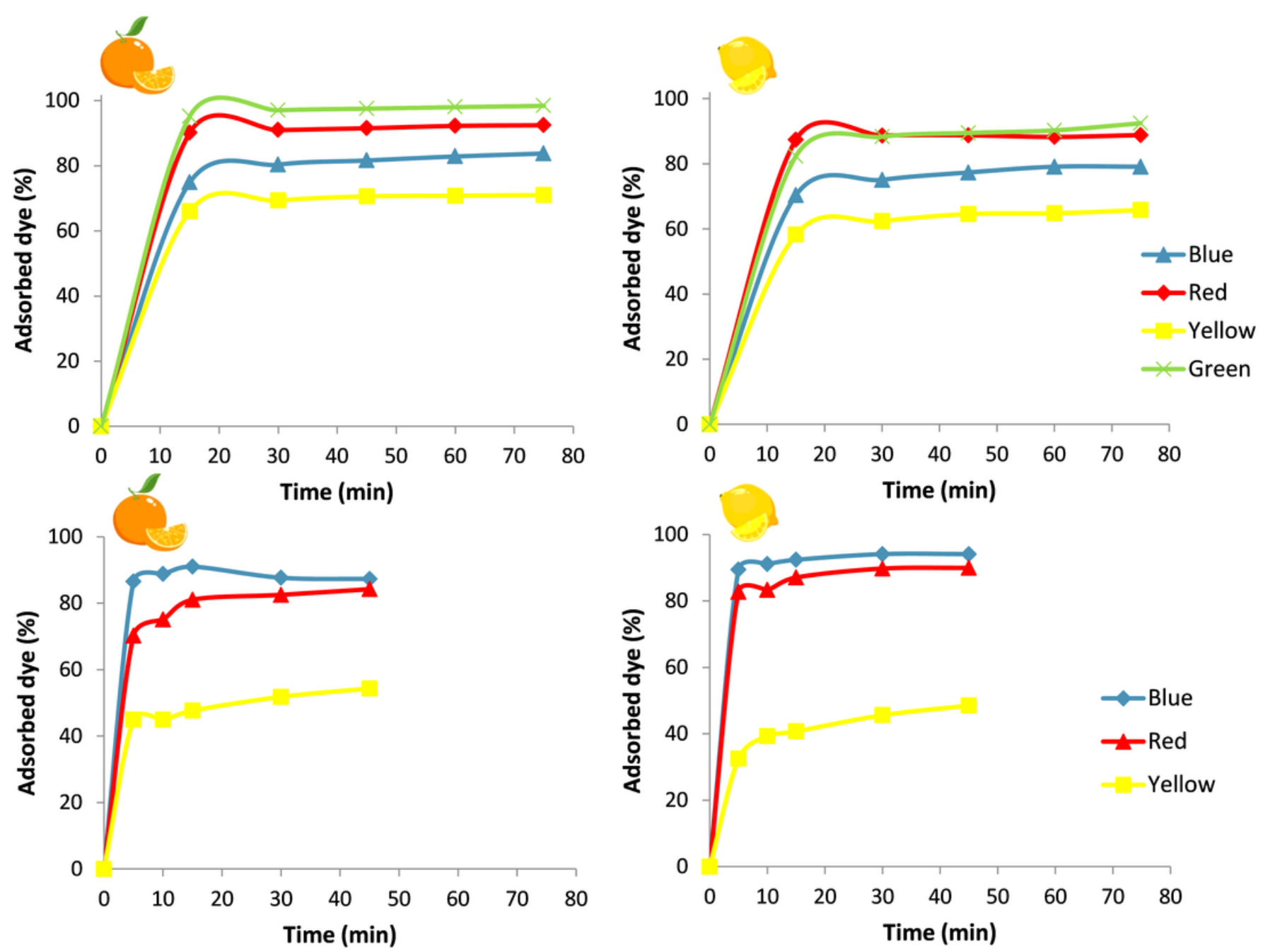

Figure 5

Percentages of adsorbed (top) cationic and (bottom) anionic dyes according to the different contact times for (left) orange-based and (right) lemon-based adsorbents. 

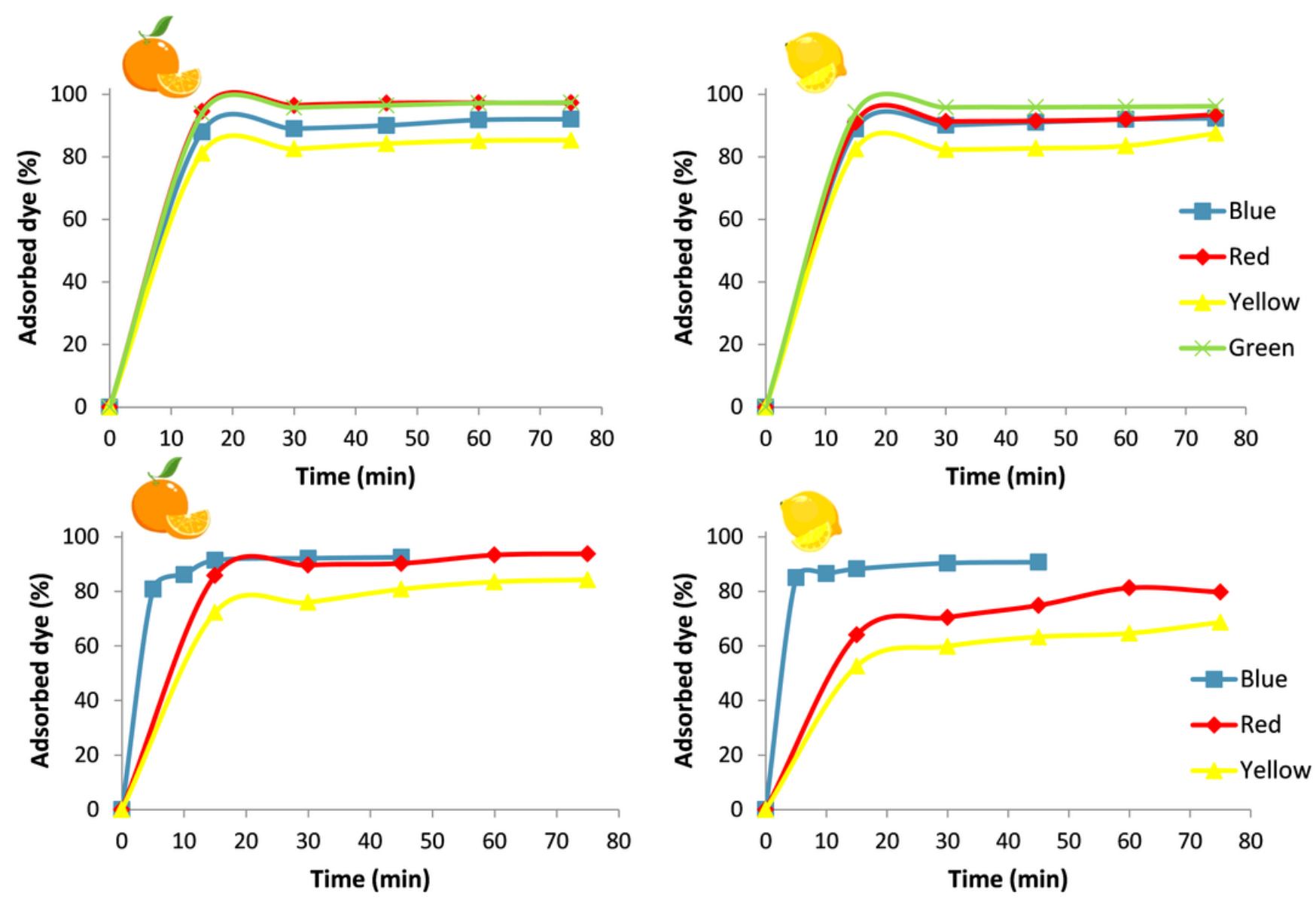

\section{Figure 6}

Percentages of adsorbed (top) cationic and (bottom) anionic dyes according to the different contact times for (left) hydrated orange-based and (right) hydrated lemon-based adsorbents. 

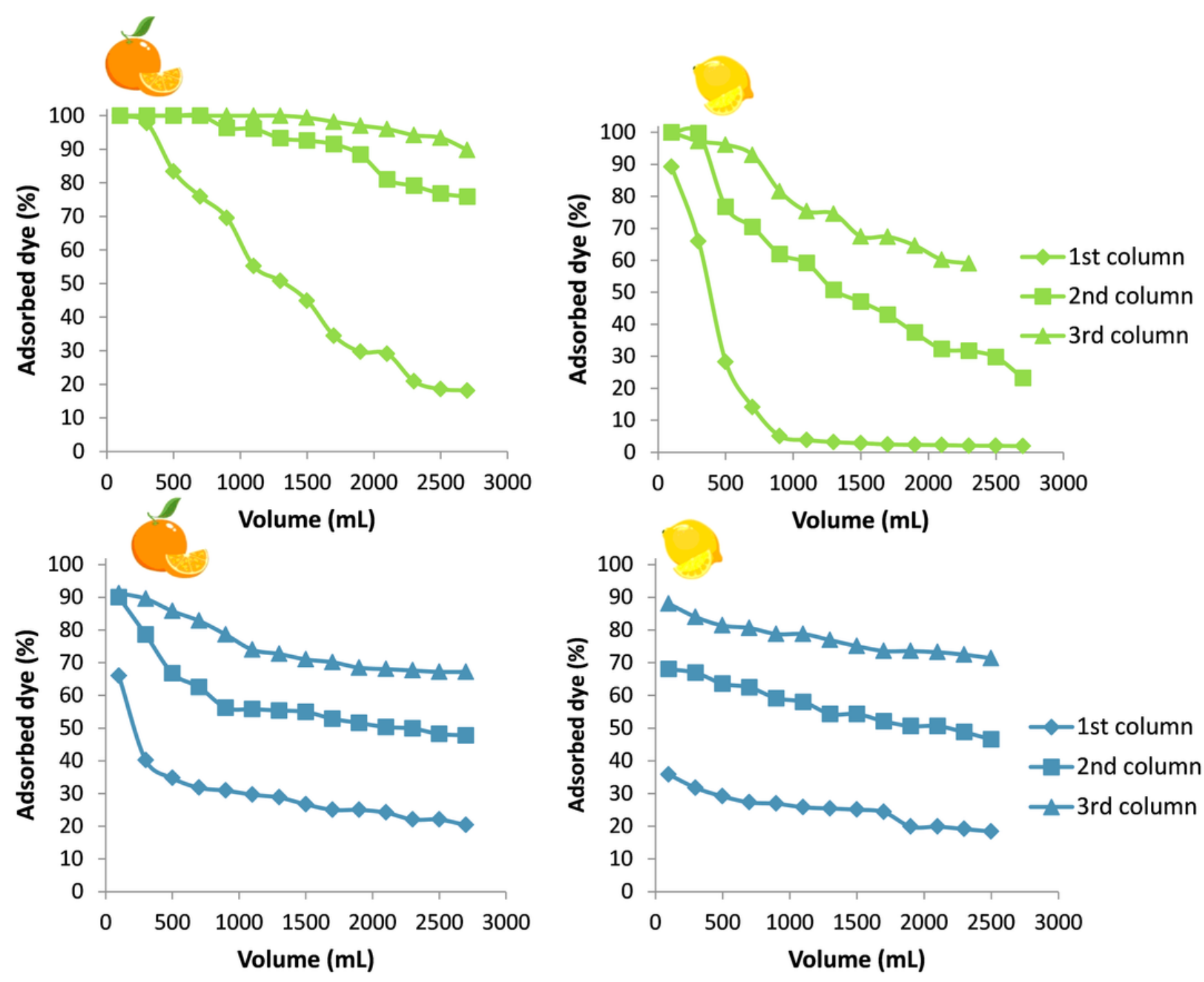

Figure 7

Percentages of adsorbed of (top) green cationic dye and (bottom) blue anionic dye vs. the volume of elution for (left) orange-based and (right) lemon-based adsorbents. 